\title{
RESEARCH
}

Open Access

\section{Reduction of $\mathrm{NgR}$ in perforant path decreases amyloid- $\beta$ peptide production and ameliorates synaptic and cognitive deficits in APP/PS1 mice}

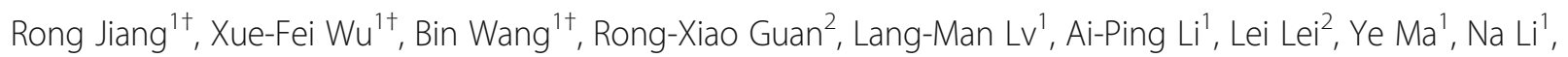
Qi-Fa Li ${ }^{1}$, Quan-Hong Ma ${ }^{3 *}$, Jie Zhao ${ }^{2^{*}}$ and Shao $\mathrm{Li}^{1^{*}}$

\begin{abstract}
Background: Amyloid beta (AB) which is recognized as a main feature of Alzheimer's disease (AD) has been proposed to "spread" through anatomically and functionally connected brain regions. The entorhinal cortex and perforant path are the earliest affected brain regions in AD. The perforant path is the most vulnerable circuit in the cortex with respect to both aging and AD. Previous data show that the origins and terminations of the perforant path are susceptible to amyloid deposition at the younger age in AD. Nogo receptor ( $\mathrm{NgR}$ ) plays an essential role in limiting injury-induced axonal growth and experience-dependent plasticity in the adult brain. It has been suggested that $\mathrm{NgR}$ is involved in AD pathological features, but the results have been conflicting and the detailed mechanism needs further investigation. In this study, the effect of $\mathrm{NgR}$ in the perforant path on the pathological and functional phenotype of APP/PS1 transgenic mice was studied.
\end{abstract}

Methods: To genetically manipulate NgR expression, adeno-associated virus (AAV) with short hairpin (shRNA) against NgR was injected into the perforant path of APP/PS1 transgenic mice, followed by an assessment of behavioral, synaptic plasticity and neuropathological phenotypes. NgR was overexpressed or knockdown in neuroblastoma N2a cells and APPswe/HEK293 cells to investigate the interaction between NgR and amyloid precursor protein (APP).

(Continued on next page)

\footnotetext{
*Correspondence: maquanhong@suda.edu.cn; dlzhaoj@163.com; lishao89@dmu.edu.cn

${ }^{+}$Rong Jiang, Xue-Fei Wu and Bin Wang contributed equally to this work.

${ }^{3}$ Jiangsu Key Laboratory of Neuropsychiatric Diseases, Institute of

Neuroscience, Soochow University, Suzhou, China

${ }^{2}$ National-Local Joint Engineering Research Center for Drug Research and

Development (R\&D) of Neurodegenerative Diseases, Dalian Medical

University, Dalian, China

'Liaoning Provincial Key Laboratory of Cerebral Diseases, Department of Physiology, College of Basic Medical Sciences, Dalian Medical University, Dalian, China
}

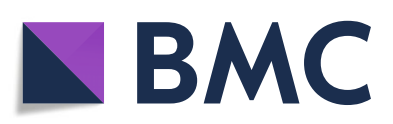

C C The Author(s). 2020 Open Access This article is licensed under a Creative Commons Attribution 4.0 International License, which permits use, sharing, adaptation, distribution and reproduction in any medium or format, as long as you give appropriate credit to the original author(s) and the source, provide a link to the Creative Commons licence, and indicate if changes were made. The images or other third party material in this article are included in the article's Creative Commons licence, unless indicated otherwise in a credit line to the material. If material is not included in the article's Creative Commons licence and your intended use is not permitted by statutory regulation or exceeds the permitted use, you will need to obtain permission directly from the copyright holder. To view a copy of this licence, visit http://creativecommons.org/licenses/by/4.0/. The Creative Commons Public Domain Dedication waiver (http://creativecommons.org/publicdomain/zero/1.0/) applies to the data made available in this article, unless otherwise stated in a credit line to the data. 
(Continued from previous page)

Results: It is shown that reduction of $\mathrm{NgR}$ in the perforant path rescued cognitive and synaptic deficits in APP/PS1 transgenic mice. Concurrently, $A \beta$ production in the perforant path and levels of soluble $A \beta$ and amyloid plaques in the hippocampus were significantly decreased. There was a positive correlation between the total APP protein level and $\mathrm{NgR}$ expression both in transgenic mice and in cultured cells, where the a-secretase and $\beta$-secretase cleavage products both changed with APP level in parallel. Finally, NgR might inhibit APP degradation through lysosome by Rho/Rho-associated protein kinases (ROCK) signaling pathway.

Conclusions: Our findings demonstrate that perforant path $\mathrm{NgR}$ plays an important role in regulating APP/A $\beta$ level and cognitive functions in AD transgenic mice, which might be related to the suppression of APP degradation by $\mathrm{NgR}$. Our study suggests that NgR in the perforant path could be a potential target for modulating AD progression.

Keywords: Alzheimer's disease, Nogo receptor, Perforant path, Amyloid precursor protein (APP), Amyloid beta, Rho/ ROCK signaling pathway

\section{Background}

Alzheimer disease (AD) is the most common cause of dementia. AD pathology is characterized by amyloid plaque formation and neurofibrillary tangle deposition. The amyloid beta $(A \beta)$ peptide is the derivative of amyloid precursor protein (APP) generated through sequential proteolytic processing by $\beta$ - and $\gamma$-secretases. APP is a transmembrane protein whose physiological function has not yet to be fully elucidated. APP subcellular localization affects the formation of $A \beta$ plaque [1-3]. For instance, accelerating the transfer of APP from early to late endosomes decreases the occurrence of APP $\beta$ cleavage [3]. Accumulative evidences have shown the crucial role of APP in triggering a complex pathophysiological cascade which leads to the neurodegenerative conditions observed in AD.

In $\mathrm{AD}$ patients, the entorhinal cortex (EC) and perforant path are the earliest affected brain regions $[4,5]$ in which neurofibrillary tangles and synaptic loss have been found [6-8]. In addition, animal studies have proved that modulation of neuronal activity via the perforant path could affect interstitial fluid $A \beta$ level and possibly subsequent $A \beta$ deposition as well [5, 9]. Intriguingly, our previous study found firstly that APP is specifically located at the node of Ranvier (NOR) in the nerve fibers [10], implicating a potential role for NORs in the A $\beta$ release. Taken together, these studies have suggested that the perforant path might play an important role in $\mathrm{AD}$ and interfere $A \beta$ metabolism in this region which may affect the progression of AD.

The Nogo-66 receptor (NgR, also termed NgR1) is an important molecule at NORs, which participates in limiting injury-induced axonal growth and experiencedependent plasticity in the adult brain [11-13]. The three myelin ligands for NgR are Nogo (also known as reticulon 4) [14-16], myelin-associated glycoprotein (MAG) [17], and oligodendrocyte myelin glycoprotein (OMgp) [18]. Most recently, intriguing studies have implicated the involvement of $\mathrm{NgR}$ in the pathogenesis of
AD. For example, expressions of $\mathrm{NgR}$ are increased in patients with AD [19]. Deleting Nogo ameliorates learning and memory deficits of APP transgenic mice at an early/intermediate stage of the disease [20]. And suppression of the Nogo/NgR pathway by NEP1-40 attenuates the deposition of $A \beta$ plaque [21]. These studies indicate that Nogo/NgR pathway might promote $\mathrm{AD}$ pathology. However, others have presented conflicting results. It has been reported that the absence of NgR increases $A \beta$ plaque load in the brain of APPswe/PSEN$1 \Delta$ E9 transgenic mice [22] and subcutaneous treatment of $\mathrm{NgR}$ (310) ecto-Fc reduces brain $\mathrm{A} \beta$ plaque load and increases the relative levels of serum $A \beta$ in the transgenic mice [23]. The controversial results might be explained by the different methods targeting NgR or Nogo. We speculate that NgR might play distinct roles in axonal pathways, and whether NgR in the perforant path regulates $A \beta$ generation and cognitive functions in $A D$ is of interest.

In this study, we find that reduction of $\mathrm{NgR}$ in the perforant path ameliorates synaptic and cognitive deficits and reduces $\mathrm{A} \beta$ deposition in APP/PS1 transgenic mice, which may be related to enhanced APP degradation through lysosome by Rho/Rho-associated protein kinases (ROCK) signaling pathway.

\section{Methods}

\section{Animals and habituation}

The male APP/PS1 transgenic mice at 6 months of age were housed in pairs, in standard cages, with free access to food and water under a 12-h light/dark cycle, controlled temperature, and humidity in specific pathogenfree conditions at the University Laboratory Animal Center.

\section{Plasmid construction and stereotaxic delivery}

We used adeno-associated virus (AAV) vectors prepared by Obio Technology (Shanghai, China) to suppress NgR expression. The small hairpin RNA (shRNA) expression 
was constructed into pAKD using Bgl II and Sal I sites. For shRNA against mouse NgR, the optimal target sequence (GATCCCCGCCGAAATCTCACTATCCT TTCAAGAGA AGGATAGTGAGATTTCGGCTTTTT) was selected, and a scrambled shRNA (GATCCCCTTC TCCGAACGTGTCACGTTTCAAGAGAACGTGACAC GTTCGGAGAATTTTTTGTAC) served as a control. The NgR shRNA sequence and control shRNA sequence were cloned into the pAKD-CMV-bGlobin-eGFP-H1shRNA vector. We then used a total of $10^{12} \mathrm{vg} / \mathrm{mL}$ of the virus to transfect the perforant path regions of mice. The recombinant vectors (AAV-vector and AAVshNgR) contained an enhanced green fluorescence protein (eGFP) as a marker to track AAV-mediated target gene expression by fluorescence microscopy. Mice were anesthetized with isoflurane and mounted onto a stereotaxic frame. AAV was injected bilaterally into the perforant path (coordinates, bregma: AP $-4.24 \mathrm{~mm}, \mathrm{ML} \pm 2.9$ $\mathrm{mm}$, and $\mathrm{DV}-1.6 \mathrm{~mm}$ ) with a slow injection rate through a microinjector attached to a digital stereotaxic arm. After injection was completed, the injector was left in place for an additional $5 \mathrm{~min}$. Mice were recovered on a heating pad upon revival.

\section{Morris water maze assessment}

The Morris water maze is used to evaluate spatial learning and memory ability of rodents [24, 25]. 8.5-monthold APP/PS1 transgenic mice were trained in the Morris water maze containing water with temperatures of $23 \pm$ $0.5^{\circ} \mathrm{C}$. The goal platform with a diameter of $10 \mathrm{~cm}$ was kept submerged $1 \mathrm{~cm}$ below the water level. The acquisition training was performed for five successive days, and each mouse participated in 4 trials per day. For the first day, mice were allowed to find the visible platform for $90 \mathrm{~s}$. From the 2nd day till the 5th day, mice were allowed to find the hidden platform. Once the mouse found the platform, it was allowed to remain there for $15 \mathrm{~s}$. If the mouse failed to find the platform in $90 \mathrm{~s}$, then the mouse was gently guided to the platform and allowed to remain there for $10 \mathrm{~s}$. The escape latency and swimming speed were analyzed. In the test phase, the platform was removed and each mouse was allowed to swim in the pool for $90 \mathrm{~s}$. Platform crossings, swimming paths, and swimming speed were recorded. Mouse activity in the aforementioned behavioral apparatuses was collected by a digital video camera connected to a computer-controlled system (Ethovision 2.0, Noldus, Wageningen, Netherlands). All tests were each blind to the treatment schedule.

\section{Passive avoidance test}

The shuttle-box apparatus is also used to evaluate the learning and memory ability of rodents [26]. The apparatus consists of a box with an illuminated area and a dark area (each area $30 \times 25 \times 18.5 \mathrm{~cm}$ ); both were equipped with a grid floor composed of steel bars. The passive avoidance task consisted of 2 trials, acquisition trial and retention trial. On the first day of training, mice were placed individually into the light compartment by a bright bulb and allowed mice to explore the boxes. The intercompartment door was opened after a 300-s acclimation period. To later adapt, if the mouse stepped into the dark compartment, an inescapable foot shock (0.1 $\mathrm{mA} / \mathrm{s}$ ) was delivered through the grid floor. The retention trial started $24 \mathrm{~h}$ after the end of the acquisition trial. Each mouse was again placed in the illuminated compartment, and the latency of mouse re-enter the dark compartment was recorded up to $300 \mathrm{~s}$. The latency in the retention trial was used as the index of retention of the learning experience. No shock was applied during the retention trial.

\section{Y-maze spontaneous alternation test}

Spontaneous alternation behavior in the Y-maze test, a behavioral test based on the animals' natural curiosity for exploration, is considered to reflect the short-term spatial working memory $[27,28]$. The apparatus for Ymaze testing is made of three opaque identical plastic arms (labeled as A, B, and C) with high walls at $120^{\circ}$ angle from each other. The mouse was introduced in the center of the maze and allowed to explore the three arms freely for $8 \mathrm{~min}$. Arm entry was defined as the entry of four limbs into one arm of the Y-maze. Entry into three different arms in succession (e.g., $\mathrm{ABC}, \mathrm{BCA}$, $\mathrm{CBA}$, or $\mathrm{CAB}$ arms) was defined as one alternation. The percent alternation score was calculated by dividing the actual number of alternations by the total number of choices minus 2 , expressed as a percentage as shown in the following equation:

Alteration $(\%)=[($ number of alterations $) /($ total arm entries -2$)] \times 100 \%$

\section{Electrophysiology and recording}

Nine-month-old APP/PS1 transgenic mice were decapitated under anesthesia with pentobarbital, and the brain was quickly removed and placed in ice-cold oxygenated artificial cerebrospinal fluid (aCSF) comprised of 110 $\mathrm{mM} \mathrm{NaCl}, 2.5 \mathrm{mM} \mathrm{KCl}, 1.5 \mathrm{mM} \mathrm{MgSO}_{4} \cdot 2 \mathrm{H}_{2} \mathrm{O}, 2.5 \mathrm{mM}$ $\mathrm{CaCl}_{2}, 1.25 \mathrm{mM} \mathrm{NaH}_{2} \mathrm{PO}_{4}, 26 \mathrm{mM} \mathrm{NaHCO}$, and 10 $\mathrm{mM}$ D-glucose ( $\mathrm{pH}$ 7.4). Coronal hippocampal slices $(400 \mu \mathrm{m})$ were prepared from the resected brains of mice using a vibratome. The slices were maintained at room temperature in aCSF bubbled with $95 \% \mathrm{O}_{2}$ and $5 \% \mathrm{CO}_{2}$ for at least $30 \mathrm{~min}$ before transfer to a submersionrecording chamber, which was continually perfused with oxygenated aCSF at the rate of $1-2 \mathrm{~mL} / \mathrm{min}$. The field excitatory postsynaptic potentials (fEPSPs) in CA1 
neurons were recorded by stimulating CA3 neurons. Long-term potentiation (LTP) was induced by applying high-frequency stimulation (HFS) (four $100 \mathrm{~Hz}$ and $1 \mathrm{~s}$ trains delivered $20 \mathrm{~s}$ apart). The LTP magnitude was quantified as the percentage change in the fEPSP slope (40\%) taken during the 60-min interval after LTP induction. The electrophysiological data were acquired with an Axon multiclamp $700 \mathrm{~B}$ amplifier, filtered at 0.1$5 \mathrm{kHz}$, and digitized at $10 \mathrm{kHz}$, and the slope and peak amplitude of fEPSP were measured and analyzed offline using pClamp10.3 software (Molecular Devices Corp, USA). Paired-pulse facilitation (PPF) is a form of shortterm synaptic plasticity, which was assessed at interstimulus intervals (ISIs) of 25, 50, 75, 100, 125, 150, and 200 $\mathrm{ms}$ in both groups of animals. The paired-pulse ratio was determined as the ratio between the second pulseevoked of fEPSP and the first one.

\section{Golgi staining for dendritic spines}

The dendritic spines were observed in the brains of 9month-old APP/PS1 transgenic mice by Golgi-Cox staining, which were performed using the FD Rapid Golgi Stain Kit (FD Neuro Technologies, Columbia, MD, USA). The tissue sections were stained according to the manufacturer's protocol. The images of hippocampal pyramidal neurons in CA1 and DG were viewed using Pannoramic MIDI Scanner (3DHistech Ltd., Budapest, Hungary) equipped with a GS3-U3-51S5M-C camera (FLIR, Canada), Lumencor SOLA (Beaverton, OR), and Semrock filters (Rochester, NY). The number of apical spines on hippocampal CA1 pyramidal neurons and DG neurons was counted. The second- or thirdorder dendritic branches were selected for quantitative analysis. The number of spines was determined per micrometer of dendritic length from 10 photographs per mouse in the digitized images. We calculated the spine density indicated by the number of spines per $10-\mu \mathrm{m}$ branches.

\section{Microdialysis and ELISA}

In vivo microdialysis was carried out according to our previous report [29]. Microdialysis enables direct assessment of interstitial fluid (ISF) $A \beta$ in the setting of intact, complex neural networks [9]. The parameters for the microdialysis probes used for in vivo experiments were as follows: $220-\mu \mathrm{m}$ OD membrane is made of hydrophilic cellulose and does not absorb A $\beta$ (MBR-1-5 brain microdialysis probe: length of the membrane was $1 \mathrm{~mm}$, $35 \mathrm{kDa}$ molecular weight cut-off; guide cannula: length of the cannula was $5 \mathrm{~mm}$; linear microdialysis probes; bioanalytical systems, West Lafayette, USA). Guide implantation surgery was performed [30,31]. Briefly, a separate group of 9-month-old AD mice were anesthetized with isoflurane and fixed in a stereotactic frame (SR-5
M, Narishige, Tokyo, Japan). The two holes were made above the hippocampus (coordinates, bregma: AP: $2.18 \mathrm{~mm}, \mathrm{ML} \pm 2.3 \mathrm{~mm}$, and DV $-2.1 \mathrm{~mm}$ ) and perforant path (coordinates, bregma: AP $-4.24 \mathrm{~mm}, \mathrm{ML} \pm 2.9$ $\mathrm{mm}$, and DV $-1.6 \mathrm{~mm}$ ). To assess ISF $A \beta$ in the hippocampus and perforant path of awake mice, in vivo microdialysis was performed. MBR-5 guide cannulas were stereotactically inserted into the brain and cemented using dental cement. The mice were kept awake during microdialysis. The constant flow rate was $1 \mu \mathrm{L} / \mathrm{min}$. Microdialysis samples were collected hourly using a refrigerated fraction collector. The concentration of $A \beta_{1-42}$ extracts in the microdialysis fractions were measured with ELISA (KHB3544, Thermo).

\section{Western blot}

Hippocampal tissues from 9-month-old APP/PS1 transgenic mice were homogenized in radioimmunoprecipitation assay buffer (RIPA buffer) and protease inhibitor cocktail. Also, cells obtained from different treatments were lysed in RIPA buffer containing a protease inhibitor cocktail. The following antibodies were used: anti-APP (1:1000, Sigma), anti-NgR (1:1000, Millipore), antisAPP $\alpha$ (1:100, IBL), anti-sAPP $\beta$ (1:500, Covance), anti- $\beta$ site APP cleaving enzyme 1 (BACE1) (1:1000, abcam), anti- $\beta$-CTF and anti- $\alpha$-CTF (1:1000, Sigma), anti-ionized calcium-binding adapter molecule 1 (Iba1) (1:1000, WAKO), glial fibrillary acidic protein (GFAP) (1:1000, DAKO) or anti- $\beta$ actin antibody (1:3000, Abcam), antiRhoA (1:1000, Sigma), and anti-ROCK2 (1:1000, Sigma). The membranes were incubated with secondary goat anti-rabbit and mouse IgG (1:5000, Thermo) and electrochemiluminescence (ECL, Millipore) reagent. The band signals were detected using BIO-RAD (Hercules, CA, USA) gel analysis software.

\section{Immunohistochemistry}

Following the brains of APP/PS1 transgenic mice, serial $10-\mu \mathrm{m}$ coronal sections were made with a cryostat (Leica CM 1850, Leica Microsystems AG, Wetzlar, Germany). Five mice per group were analyzed, and nine hippocampal sections from each APP/PS1 transgenic mouse were selected for immunohistochemical staining. The sections were stained with $0.05 \% 3,3^{\prime}$-diaminobenzidine (DAB). Whole images were captured using a Pannoramic MIDI (3D Histech, Hungary) equipped with a GS3-U3-51S5MC camera (FLIR, Canada), Lumencor SOLA (Beaverton, OR), and Semrock filters (Rochester, NY). The $A \beta$ plaque load was quantified by the areas of $A \beta$ plaques in the cortex and hippocampus divided by the total area of the corresponding sites. The microglia- and astrocytepositive area were quantified as the $\mathrm{GFAP}^{+}$or $\mathrm{Iba}^{+}$area divided by the total area of the hippocampus. Image-Pro 
Plus 6.0 image analysis software (Media Cybernetics, MD, USA) was used to analyze the images.

\section{Cell cultures, transfection, and treatments}

HEK293 cells stably expressing human APP695 Swedish mutant (APPswe/HEK293 cells) were grown in Dulbecco's modified Eagle's (DMSO) medium supplemented with $10 \%$ fetal bovine serum and maintained in medium containing $400 \mu \mathrm{g} / \mathrm{mL} \mathrm{G418.} \mathrm{According} \mathrm{to} \mathrm{the} \mathrm{gene} \mathrm{se-}$ quence of mouse $\mathrm{NgR}$, a small interfering RNA (siRNA) targets NgR. The siRNA was designed and synthesized by Sigma (Shanghai, China). The sequences were as follows:

NgR siRNA, sense: 5'-UUCUCCGAACGUGUCACGUTT-3'

antisense: 5' -ACGUGACACGUUCGGAGAATT-3'

Control siRNA, sense: 5'-GCCGAAAUCUCACU AUCCUTT-3'

antisense: 5' -AGGAUAGUGAGAUUUCGGCTT-3'

Plasmids carrying specific NgR gene shRNA and control shRNA were constructed by Obio Technology, Shanghai, China. The sequences were as follows:

NgR shRNA, sense: 5'-GATCCCCGCCGAAATCTC ACTATCCTTTCAAGAGA AGGATAGTGAGATTTC GGCTTTTT-3'

control shRNA, sense: 5'-GATCCCCTTCTCCG AACGTGTCACGTTTCAAGAGA ACGTGACACG TTCGGAGAATTTTTTGTAC-3'

The overexpression of NgR human NgR-coding DNA fragments were generated and inserted into pCDNA-CMV vector (GenePharma, Shanghai, China). APPswe/HEK293 cells and neuroblastoma N2a cells were harvested $48 \mathrm{~h}$ post-transduction. For transfections, equivalent amounts of cells were plated, and transfections were performed using Lipofectamine 3000 (Invitrogen, USA) according to the manufacturer's instructions. For Rho inhibition, Y-27632 (Selleck, USA) and Fasudil (Selleck, USA) were dissolved in $\mathrm{H}_{2} \mathrm{O}$. Forty-eight-hour post-transduced cells were treated with drugs at $50 \mu \mathrm{M}$ for $10 \mathrm{~h}$.

\section{Reverse transcriptase-PCR (RT-PCR)}

Total RNA was extracted from hippocampal tissue and cells with the TRIzol reagent according to the manufacturer's instructions. Primed RNA $(1 \mu \mathrm{g})$ was reversetranscribed with TransScript One-Step gDNA Removal and cDNA Synthesis Super Mix (TransGen Biotech, Beijing, China). The primers for NgR, APP, and the housekeeping gene GAPDH (Life Technologies, Thermo Fisher Scientific-CN, Shanghai, China) are listed in Table 1. The thermocycling conditions for real-time PCR were $95^{\circ} \mathrm{C}$ for $2 \mathrm{~min}$, followed by 30 cycles of $94{ }^{\circ} \mathrm{C}$ for $45 \mathrm{~s}, 60^{\circ} \mathrm{C}$ for $45 \mathrm{~s}$, and $72{ }^{\circ} \mathrm{C}$ for $60 \mathrm{~s}$. Following 30 cycles, elongation was performed at $72{ }^{\circ} \mathrm{C}$ for $5 \mathrm{~min}$. The
Table 1 Primer sequences for RT-PCR analysis

\begin{tabular}{ll}
\hline Target mRNA sequences & Primer sequence \\
\hline APP (human) & 5'-GGCGGAGCAGACACAGACTA-3' \\
NgR (human) & 5'-ACCTCATCACCATCCTCATCGT-3' \\
& 5'-ATGCTACAATGAGCCCAAGG-3' \\
5APDH (human) & 5'-GAGCTGTGCATTATCGCTGA-3' \\
& 5'-TGGTGAAGACGCCAGTGGA-3' \\
APP (mouse) & 5'-GGCCCTCGAGAATACATCA-3' \\
& 5'-GTTCATGCGCTCGTAGATCA-3' \\
GAPDH (mouse) & 5'-TCACCACCATGGAGAAGGC-3' \\
& 5'-GCTAAGCAGTTGGTGGTGCA-3' \\
\hline
\end{tabular}

PCR products were analyzed by densitometry using BIO-RAD (Hercules, CA, USA) gel analysis software.

\section{Immunofluorescence}

APPswe/HEK293 cells were coated coverslips in 24-well culture dishes before transfection. After transfection, cells were incubated with primary antibodies including rabbit anti-APP (1:100, Sigma), mouse anti-EEA1 (1:100, cell signaling technology), mouse anti-Rab7 (1:50, abcam), and mouse anti-LAMP1 (1:10, abcam). The images were captured using a Pannoramic MIDI (3D Histech, Hungary) equipped with a GS3-U3-51S5M-C camera (FLIR, Canada), Lumencor SOLA (Beaverton, OR), and Semrock filters (Rochester, NY). Pearson's coefficients of colocalization were analyzed by ImageJ (NIH).

\section{Statistical analysis}

All values were reported as mean \pm SEM. Simple comparisons between two groups were analyzed using the Student 2-tailed unpaired $t$ test. Multiple comparisons between the groups were performed using 2-way ANOVA followed by post hoc analysis on SPSS 20.0 software. The escape latency in the Morris water maze was analyzed by two-way repeated measures ANOVA. Prism software (GraphPad Software) was used for all the graphs. A value of $P<0.05$ was considered statistically significant.

\section{Results}

Knockdown of $\mathrm{NgR}$ in the perforant path attenuates cognitive deficits in APP/PS1 transgenic mice

Cognitive deficits are the early component of AD. In order to examine whether the perforant path $\mathrm{NgR}$ impacts learning and memory, we knocked down NgR of the perforant path by stereotactic injecting AAV into the perforant path of 6-month-old APP/PS1 transgenic mice. Three months after the injection, GFP labeling was detected by fluorescence imaging to confirm the location of injection (Additional file 1: Figure S1 A-B). Western 
blotting was used to confirm a strong reduction of $\mathrm{NgR}$ in the perforant path by AAV-shNgR injection (Additional file 1: Figure S1 C-D). Animals were subjected to a series of behavioral tests including Morris water maze, passive avoidance, and Y-maze.

The Morris water maze test was performed to examine the effect of knockdown of $\mathrm{NgR}$ on spatial working memory. The analysis of variance for repeated measures indicated a significant effect in the acquisition phase of learning (a latency to find the platform) $\left[F_{(1,20)}=106.095, p<0.001\right]$. The AAVshNgR APP/PS1 transgenic (TG-shNgR) mice exhibited improved learning in the task of locating the escape platform, which was indicated by the decreased escape latencies during the trials on the 5th day compared to the control (TG-vector) mice; the TG-shNgR mice exhibited shorter escape latency (Fig. 1A (a)). The repeated measures ANOVA showed a significant difference between-subjects effects $\left[F_{(1,} 20\right)=4.446$, $p=0.048]$ and no significant difference within-subjects effects (time $\times$ group) $\left[F_{(4,80)}=2.047, p=0.096\right]$. Representative swimming traces of mice are shown in Fig. 1A (b). No significant difference was shown in the swimming speed between the two groups (Fig. 1A (c, d)), which could eliminate the interference of swimming speed to the escape latencies [32]. In the probe trial, TG-shNgR mice showed improved memory retention by recording significantly increased number of platform crossing than TG-vector mice (Fig. 1A (e)). The proportion of time spent in the target quadrant by TG-shNgR mice was significantly higher than that by TG-vector mice (Fig. 1A (f)). These results demonstrated that the downregulation of $\mathrm{NgR}$ ameliorated the impaired learning and memory function in the APP/PS1 transgenic mice.

The passive avoidance test was used to detect the emotional learning and memory. In the acquisition session (training; day 1), no significant differences in the latency to enter the dark compartment were observed between the two groups (Fig. 1B (a)). Meanwhile, the latency of $\mathrm{TG}$-shNgR mice to the dark compartment was prolonged compared to the TG-vector mice on the second day (Fig. 1B (b)), suggesting that downregulation of $\mathrm{NgR}$ significantly improved the emotional learning and memory in the APP/PS1 transgenic mice.

In the Y-maze test for short-term spatial memory, the percentage of alternation was significantly increased in TG-shNgR mice compare with TG-vector mice even though the total number of entries was not affected significantly (Fig. 1C). Taken together, the $\mathrm{NgR}$ reduction could improve the short-term and long-term memory functions and rescue the cognitive deficits in APP/PS1 transgenic mice.

\section{$\mathrm{NgR}$ reduction improves synaptic plasticity in APP/PS1 transgenic mice}

Cognitive impairment is strongly associated with synaptic loss and synaptic functional abnormalities induced by $\mathrm{A} \beta$ deposit in $\mathrm{AD}$ [33]. Thus, we investigated whether the downregulation of NgR could prevent impairments in synaptic plasticity in the hippocampus. LTP is widely considered to be one of the major cellular mechanisms of learning and memory [34]. In our study, it was induced by HFS in the CA1 region of 9-month-old TGshNgR mice and TG-vector mice (Fig. 2A (a, b)). TGvector mice showed a lower LTP compared with TGshNgR mice indicated by a significant reduction in the fEPSP slope (Fig. 2A (c)) and fEPSP peak amplitude (Fig. 2A (d)). At the same time, the PPF in the hippocampal CA1 region was measured immediately. There was no significant difference between the two groups (Fig. 2A (e)). These results demonstrated that reducing $\mathrm{NgR}$ expression in the perforant path by AAV-shNgR improves LTP of APP/PS1 transgenic mice. Loss of dendritic spines in the hippocampus contributes to LTP and cognition impairment in APP/PS1 transgenic mice [33]. We therefore studied whether NgR knockdown might improve spine density in the brains of APP/PS1 transgenic mice using Golgi staining. The TG-shNgR mice showed significant increases in the density of spines in CA1 and DG compared with TG-vector mice (Fig. 2B (a, b)). The results indicated that decreasing the expression of $\mathrm{NgR}$ could prevent the loss of spines of APP/PS1 transgenic mice. All these results indicate that the downregulation of $\mathrm{NgR}$ improves synaptic plasticity in APP/PS1 transgenic mice.

\section{Downregulation of $\mathrm{NgR}$ reduces $\mathrm{A} \beta$ deposition}

Based on the results that $\mathrm{NgR}$ reduction could rescue cognitive deficits, which has been identified as a major consequence of increased $A \beta$ production, we reasoned that changes in the $\mathrm{NgR}$ of the perforant path may have an effect on $A \beta$ generation. Soluble $A \beta$ in ISF has been shown to reflect total soluble $A \beta$ in extracellular pools and is significantly correlated with the amyloid deposition of the brain [30,35]. Microdialysis has contributed a very important technology to the evaluation of soluble $\mathrm{A} \beta$ in $\mathrm{AD}[30,31,36,37]$. We used microdialysis to assess ISF $A \beta_{1-42}$ metabolism both in the perforant path and hippocampus of APP/PS1 transgenic mice (Fig. 3A (a)). The ISF $A \beta$ concentrations in the perforant path (Fig. 3A (b)) and hippocampus (Fig. 3A (c)) of TGshNgR mice decreased in comparison with TG-vector mice. In addition to soluble $A \beta$ analysis, coronal sections of the cortex and hippocampus were stained with an antibody against $\mathrm{A} \beta$ in APP/PS1 transgenic mice (Fig. 3B (a), C (a)). Quantification analysis showed that the size (Fig. 3B (b) and C (b)) and numbers (Fig. 3B (c) and C 
$A_{\text {(a) }}$

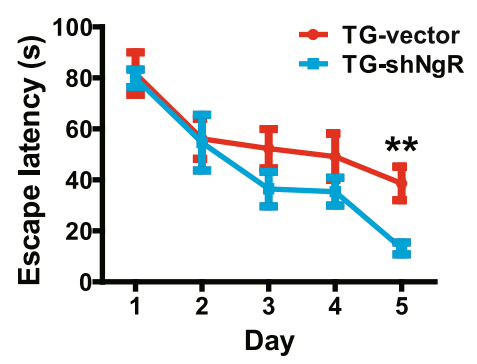

(d)

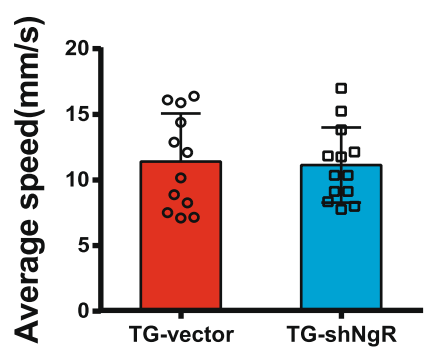

B (a)

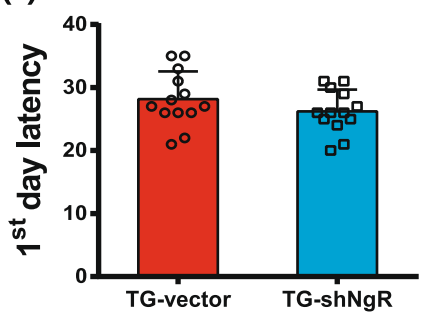

(b)

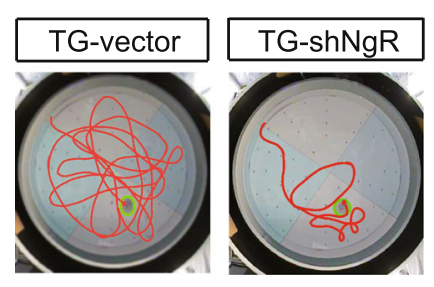

(e)

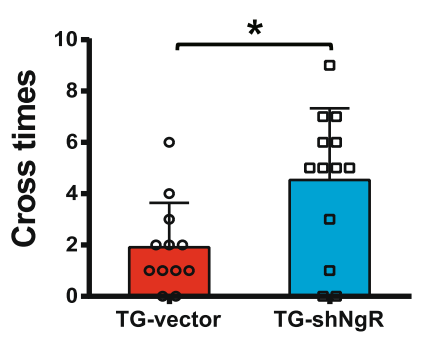

(b)

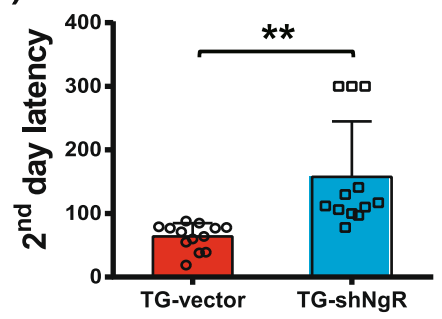

(c)

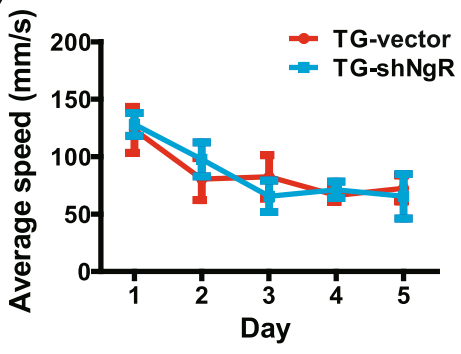

(f)

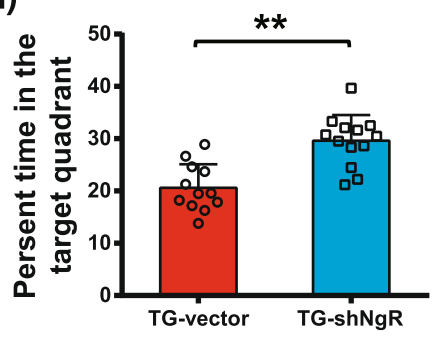

C

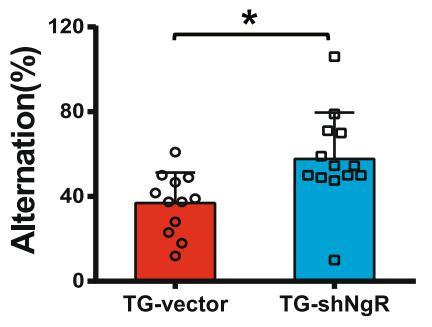

Fig. 1 Knockdown of NgR in the perforant path attenuates cognitive impairment in APP/PS1 transgenic mice. TG-vector: AAV-vector APP/PS1 transgenic mice. TG-shNgR: AAV-shNgR APP/PS1 transgenic mice. A Mice were subjected to the Morris water maze test, $\mathbf{B}$ the passive avoidance test, and the $\mathbf{C}$ Y-maze spontaneous alteration test. $\mathbf{A}(\mathrm{a})$ The mean escape latency. $\mathbf{A}(\mathrm{b})$ Tracings of the typical swim patterns. $\mathbf{A}$ ( $\mathbf{C}$, d) The swimming speed during the acquisition training and the test phase. $\mathbf{A}(\mathrm{e})$ The number of crossing of the platform area. $\mathbf{A}$ ( $\mathrm{f}$ ) The percentage of the time spent by the mice in the target quadrant. B $(\mathrm{a}, \mathrm{b})$ The latency of APP/PS1 transgenic mice during the passive avoidance test. $\mathbf{C}$ The alternation score of the Y-maze spontaneous alteration test. Data are presented as mean \pm SEM. $n=13$ male mice/group. Data in $\mathbf{A}$ (a) and (c) were analyzed by repeated measures ANOVA with post hoc test, ${ }^{* *} P<0.01$. Data in $\mathbf{A}(\mathrm{d}, \mathrm{f}), \mathbf{B}$, and $\mathbf{C}$ were analyzed by Student's $t$ test, TG-shNgR mice vs TG-vector mice. ${ }^{*} P<0.05$; ${ }^{*} P<0.01$

(c)) of $A \beta$ plaques were significantly reduced in the cortex and hippocampus of TG-shNgR mice compared with TG-vector mice. These results suggest an inhibitory effect of reducing $\mathrm{NgR}$ in the perforant path on the generation and accumulation of $A \beta$ plaques in APP/PS1 transgenic mice.

$\mathrm{NgR}$ reduction suppresses the activation of microglia and astrocytes in APP/PS1 transgenic mice

Astrocyte and microglia activation is associated with amyloid plaque formation, neuronal and synaptic dysfunction, cell death, and further neurodegeneration [38, 39]. Neuroinflammation has been recognized as an important cause of AD and is associated with disease severity. Thus, we addressed whether NgR knockdown would inhibit glial activation in APP/PS1 transgenic mice. We performed immunohistochemical staining on coronal sections of the hippocampus with antibodies against Iba-1 and GFAP (markers for microglia and astrocyte respectively) (Fig. 4A (a), B (c)). The results showed that the positive cells and area percentage of both microglia and astrocytes in the hippocampus of TG-shNgR mice decreased compared with TG-vector mice (Fig. 4A (b, c), B (d, e)). Western blot analysis also confirmed the above results (Fig. 4A (d, e), B $(\mathrm{a}, \mathrm{b})$ ). These results suggest that downregulation of NgR can attenuate glial activation induced by amyloid plaques in APP/PS1 transgenic mice.

\section{$\mathrm{NgR}$ affects APP processing}

There are both amyloidogenic and non-amyloidogenic processing of APP, and decreased A $\beta$ could be the result of increased $\alpha$-secretase cleavage and decreased $\beta$ - 
$A_{(a)} \quad$ (b)

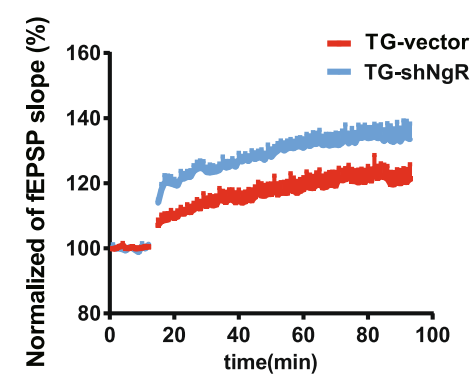

(d)

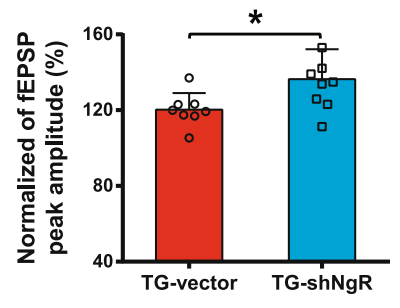

(e)

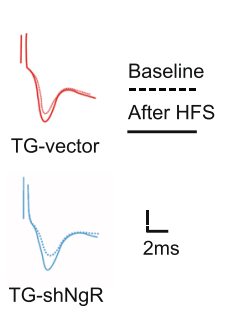

(c)

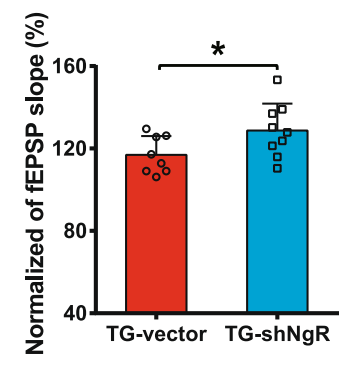

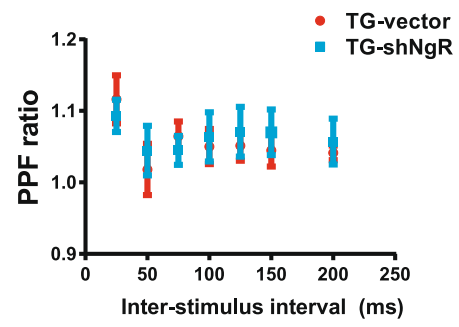

(b)
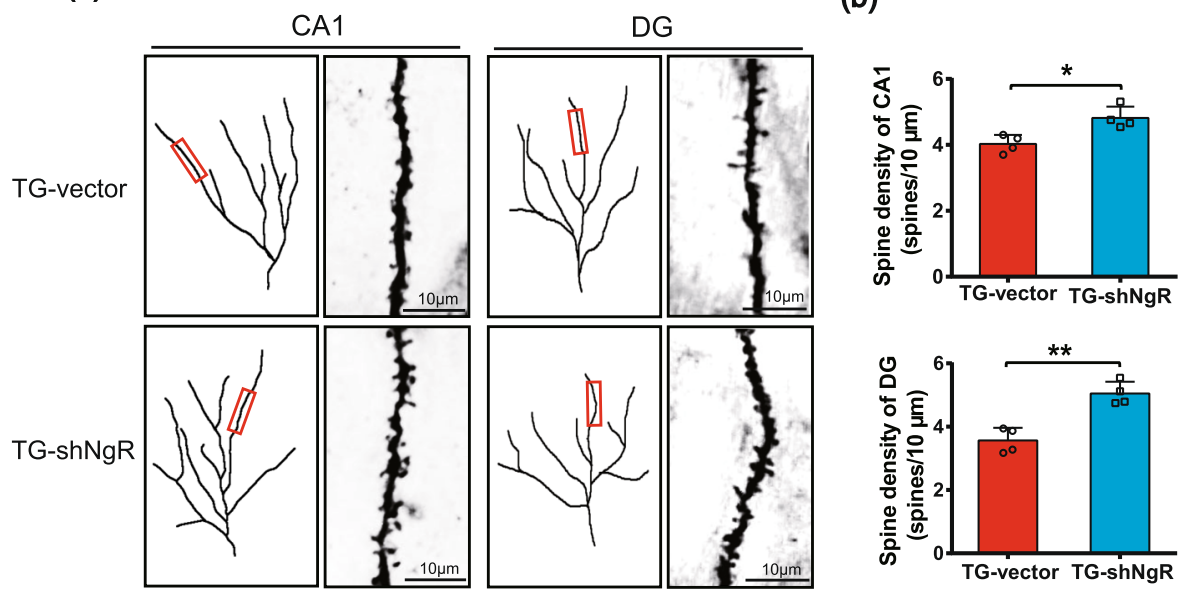

Fig. $2 \mathrm{NgR}$ reduction improves synaptic plasticity in APP/PS1 transgenic mice. A (a) The effects of HFS on the fEPSP initial slope. A (b) Representative fEPSP traces for data shown. A (c) Cumulative data showing the mean fEPSP slope 60 min post-HFS. A (d) Cumulative data showing the mean fEPSP peak amplitude 60 min post-HFS. A (e) Cumulative data showing the PPF ratio. B (a) Analysis of the density of spines of each group of mice at 9 months of age. $\mathbf{B}(b)$ The density of spines in the hippocampus of each group of the mice was analyzed. Scale bars $10 \mu \mathrm{m}$. Data are presented as mean \pm SEM. $n=4$ male mice/group. The statistical analysis was performed by Student's $t$ test. ${ }^{*} P<0.05 ;{ }^{* *} P<0.01$

secretase cleavage. We quantified the products of $\alpha$ - and $\beta$-secretases' cleavage, a large $\alpha$ - and $\beta$-fragment ectodomain of APP (sAPP $\alpha$ and SAPP $\beta$ ), and the corresponding small cytoplasmic fragments, $\alpha-C T F$ and $\beta-C T F$, in order to understand why NgR knockdown decreases $A \beta$ level. Both sAPP $\alpha / \alpha-C T F$ and $s A P P \beta / \beta$-CTF were decreased significantly in the hippocampus in TG-shNgR mice, compared with TG-vector mice (Fig. 5A (a, b)). BACE1 protein expression level showed no significant difference between the two groups. Additionally, APP protein levels of TG-shNgR mice were substantially less than those of TG-vector mice (Fig. 5A (a, b)) and APP mRNA levels remained unaffected by $\mathrm{NgR}$ reduction (Fig. $5 \mathrm{~A}$ (c)).

Next, we performed the in vitro experiments to further confirm the above results. We knocked down NgR effectively using shRNA constructs in neuroblastoma N2a cells (Fig. 5B (a)). Densitometry analysis indicated that APP protein was obviously reduced following RNAi downregulation of NgR (Fig. 5B (b)). In APPswe/HEK293 cells that express mutant APP, NgR knockdown by siRNA interference also 


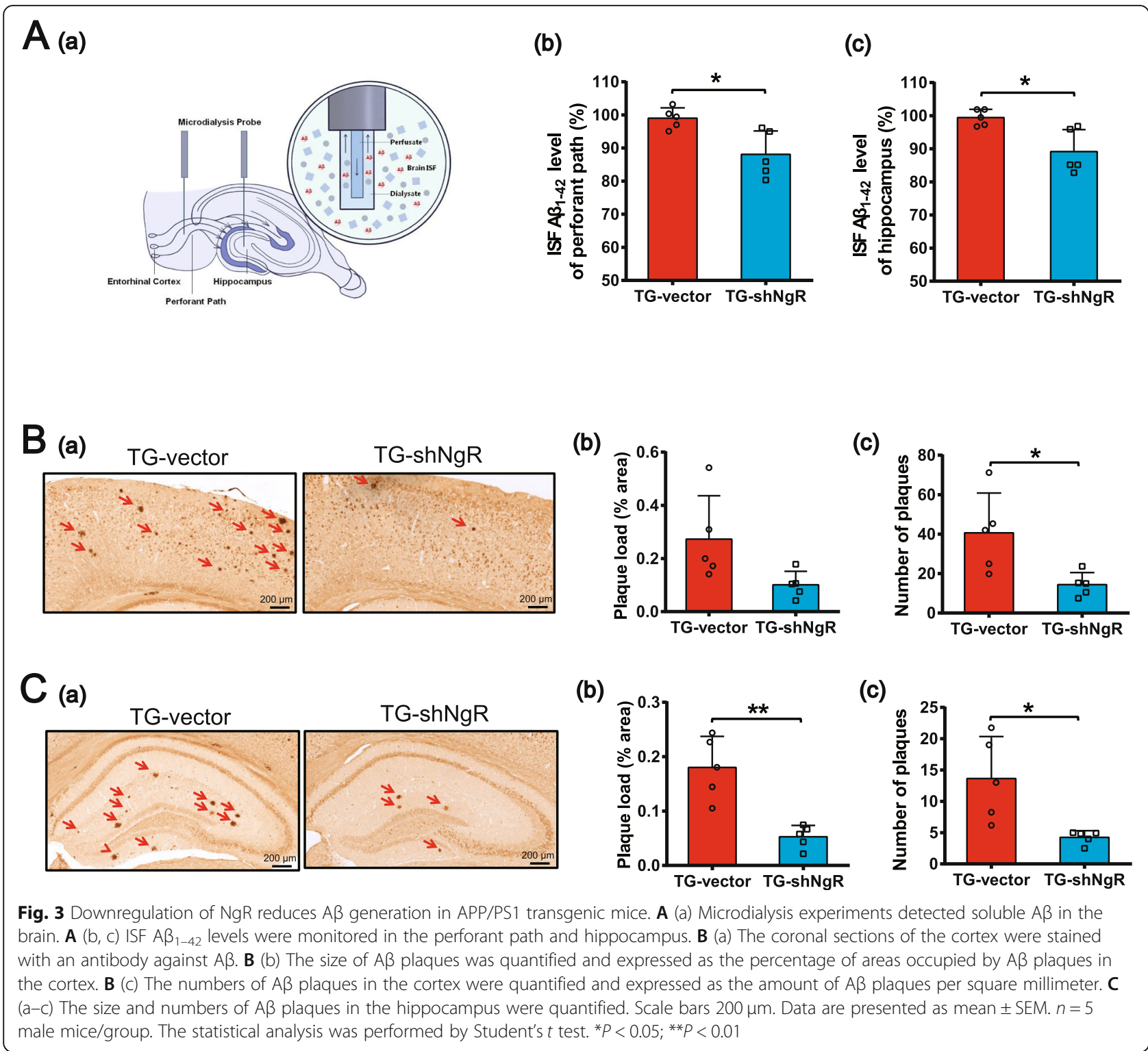

significantly decreased the protein level of APP (Fig. 5C (a, b)). Overexpression of NgR in APPswe/HEK293 cells significantly increased the APP protein level as well as the sAPP $\alpha$ and SAPP $\beta$ production (Fig. 5D (a, b)), while the mRNA levels of APP did not change significantly by overexpression of NgR (Fig. 5D (c, d)).

Both in vivo and in vitro results showed that $\mathrm{NgR}$ had the same effect on the total APP protein level and $\alpha / \beta$ secretase cleavage, suggesting NgR might interfere with the intracellular process that reduces APP supply for both the amyloidogenic and non-amyloidogenic pathways.

\section{$\mathrm{NgR}$ reduction promotes APP traffic to lysosomes by Rho/ ROCK pathway}

Intracellular APP trafficking is critical for APP localization and processing. NgR, the receptor of myelin inhibitors, increases the GTP bound state of the neuronal cytoskeleton regulatory factor RhoA, to activate the RhoA/ROCK pathway [40]. And it is reported that inhibition of ROCK2 activity may reduce the amyloidogenic process from APP [2]. Our result showed that the levels of RhoA and ROCK2, but not ROCK1 of TG-shNgR mice were significantly decreased (Fig. 6A (a, b)). Furthermore, the in vitro experiment demonstrated that the RhoA and ROCK2 levels in siNgR-treated APPswe/HEK293 cells were significantly decreased (Fig. 6B (a, b)).

Therefore, we hypothesized that inhibiting ROCK may result in the reduction of APP. To determine this speculation, APPswe/HEK293 cells were treated with Y-27632 (ROCK1 antagonist) and Fasudil (ROCK2 antagonist) respectively and the protein levels of APP were examined by Western blot assay. The quantitative results showed 


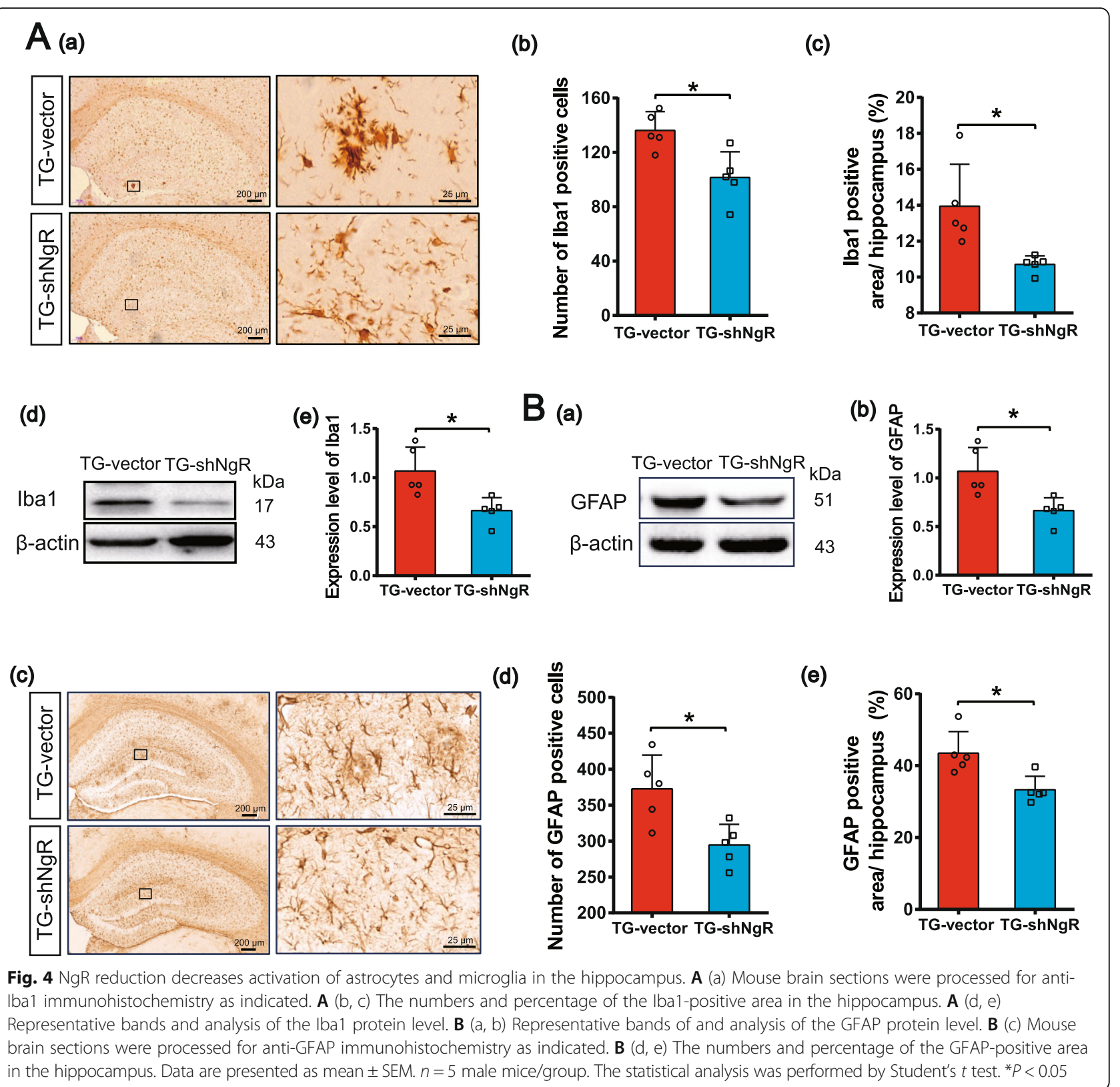

that Fasudil remarkably decreased the APP level (Additional file 2: Figure S2). Subsequently, APPswe/HEK293 cells with overexpression of NgR were treated with Y27632 and Fasudil respectively and the protein levels of APP and NgR were examined by Western blot assay (Fig. 6C (a), D (a)). The quantitative results showed that inhibiting the activity of ROCK2 kinase, not ROCK1 kinase, could reverse the elevation of APP protein induced by overexpression of $\mathrm{NgR}$ (Fig. 6C (b, c), D (b, c)). As RhoA/ ROCK2 pathway is involved in APP degradation in lysosome [2], so we examined whether NgR modulates APP transport to lysosome. NgR was reduced in APPswe/ HEK293 cells growing on coverslips. After $48 \mathrm{~h}$, the cells were stained for APP and markers for early endosomes
(EEA1), late endosomes (Rab7), or lysosomes (LAMP1) (Fig. 6E (a)). Confocal microscopy observation showed that APP colocalization with EEA1 was reduced whereas APP colocalization with LAMP1 was markedly increased by NgR reduction (Fig. 6E (b)). APP colocalization with Rab7positive compartments also appeared elevated by NgR silence although the difference was not statistically significant (Fig. 6E (b)). These observations suggest that NgR reduction decreases the APP presence in early endosomes and promotes APP traffic to lysosomes by Rho/ROCK2 pathway.

\section{Discussion}

The exact mechanisms of APP contributing to the development of dementia are unknown by far, but cleavage of 


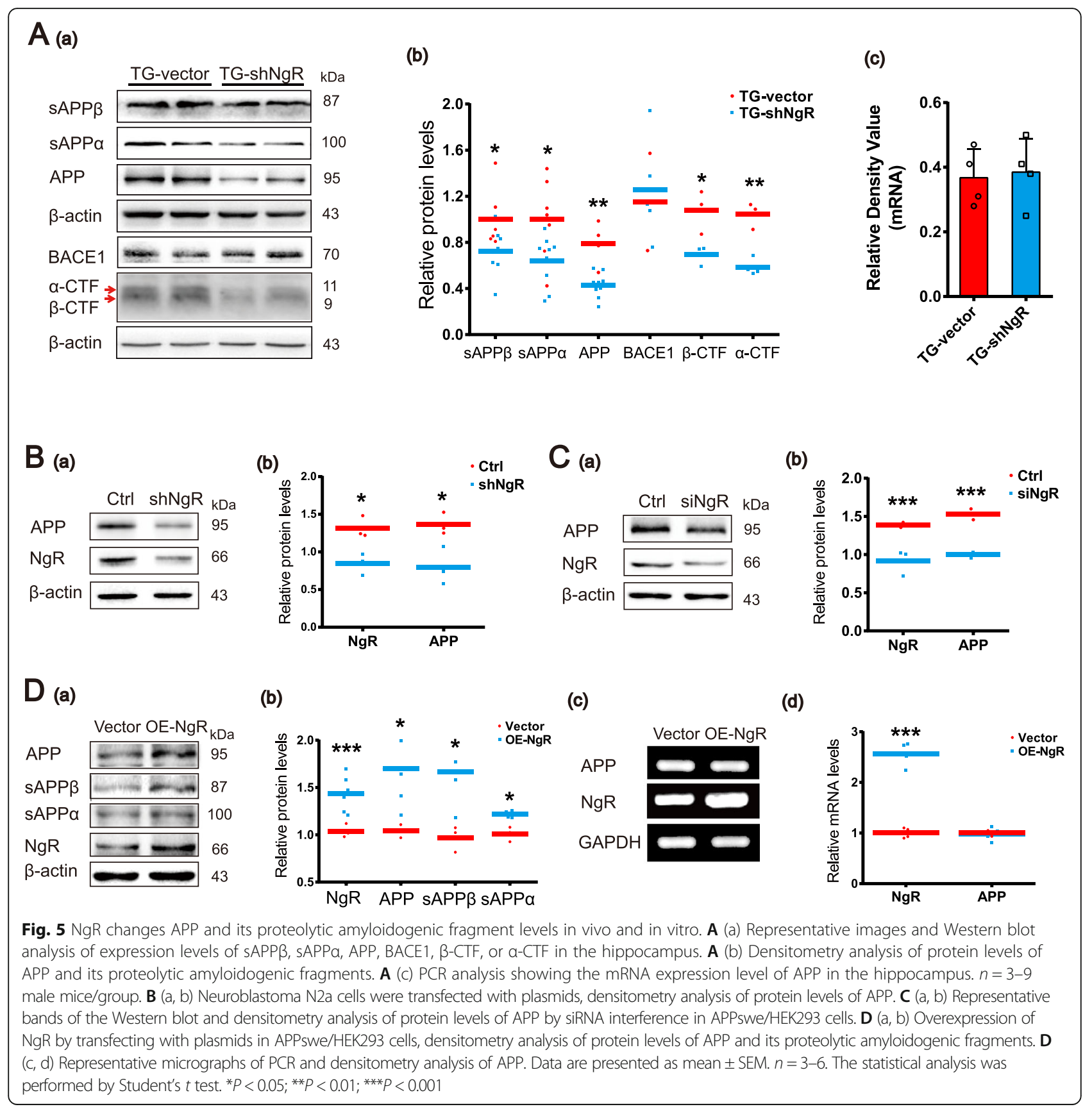

APP by secretases leading to the formation of a smaller peptide, $A \beta$, is considered a crucial step. Deposition of $A \beta$ is widely regarded as a marker of the pathology of $\mathrm{AD}$ and is associated with other pathological changes such as the brain cell death, accumulation of amyloid plaques, and appearance of neurofibrillary tangles. In $A D$ patients, the $\mathrm{EC}$, origination of the perforant path, is one of the most severely affected areas, particularly at earlier stages of the disease [4]. Moreover, electrical activity within the pathway modulates interstitial fluid $A \beta$ levels, which can be blocked by tetrodotoxin (TTX), a specific sodium channel blocker [9]. NORs are the naked regions of the axolemma and intermittently distribute along myelinated axons, implying potential interactions between exposed axonal molecules and the extracellular partners. According to our previous observation that APP is specifically located at NORs in the central nervous system [10], we propose that the NORs, to some extent, are important $A \beta$ releasing sites, which correlate with its deposition along the perforant path at the onset of $\mathrm{AD}$.

$\mathrm{NgR}$ is an important molecule at NORs, which participate in limiting injury-induced axonal growth and 


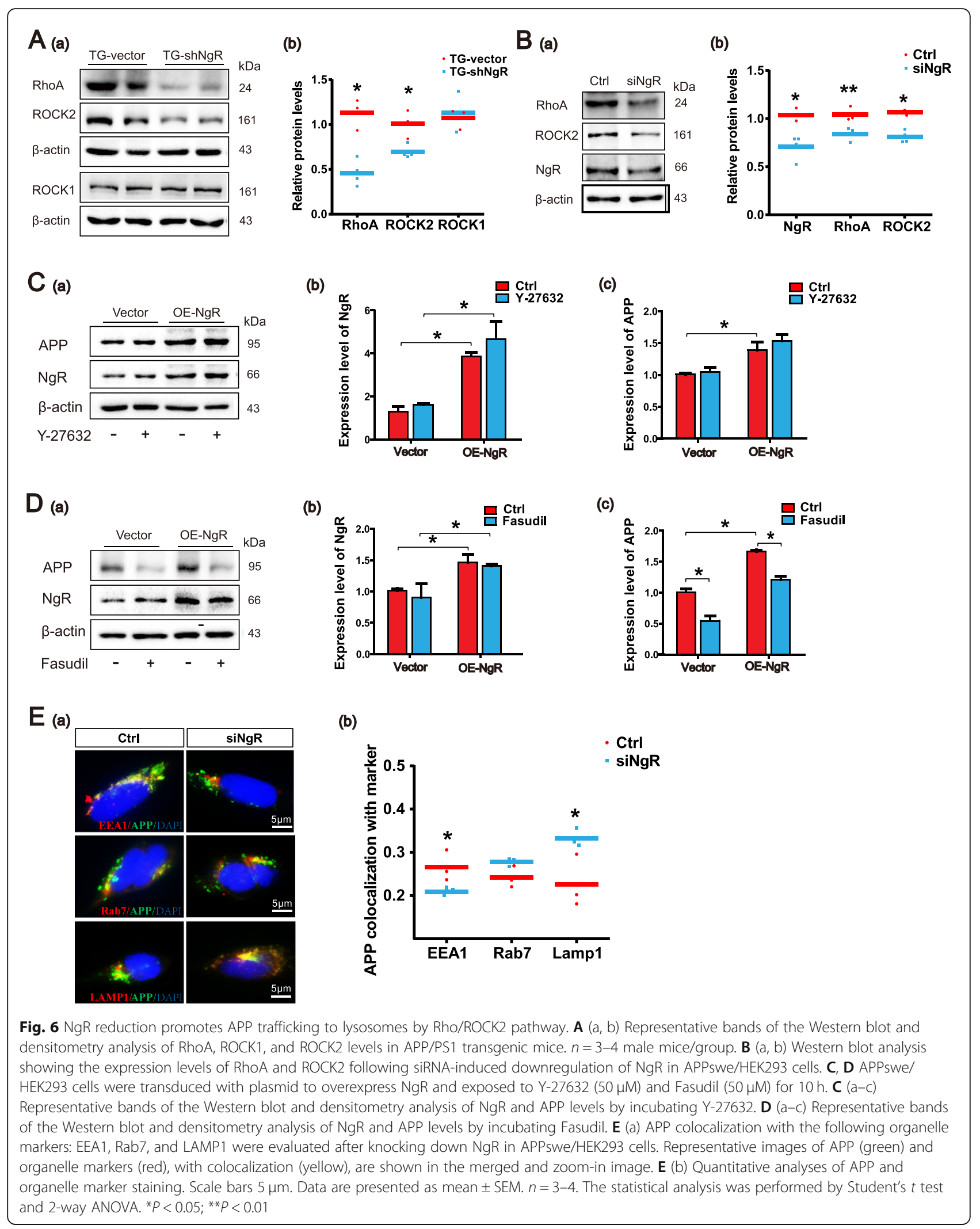


experience-dependent plasticity in the adult brain $[12,13]$. In this role, it serves as a receptor for three myelin inhibitor proteins, Nogo, MAG, and OMgp, signaling to activate Rho GTPase in axons $[13,40]$. Recently, it is reported that $\mathrm{NgR}$ is involved in AD pathological features, but the results have been conflicting and the detailed mechanism needs further investigation. In the current study, $\mathrm{NgR}$ knockdown in the perforant path was shown to ameliorate the cognitive and synaptic deficits in APP/PS1 transgenic mice (Figs. 1 and 2), which could be attributed, at least in part, to the reduced level of soluble and deposited $A \beta$ (Fig. 3) and related weakened neuroinflammation (Fig. 4). Because $A \beta$ is generated and released from neuronal terminals into the extracellular space, activity-related changes in $A \beta$ levels would likely occur and are able to detect immediately in brain interstitial fluid. Microdialysis enables direct and frequent assessment of ISF A $\beta$ concentrations in the setting of intact, complex neural networks. To determine whether knockdown $\mathrm{NgR}$ in the perforant path influences ISF A $\beta$ levels in vivo, microdialysis probes were inserted into the hippocampus and perforant path separately to measure ISF A $\beta$ levels from the awake APP/ PS1 transgenic mice. A sensitive ELISA for $A \beta_{1-42}$ was used to assess ISF $A \beta$. We found that ISF $A \beta$ concentrations both in the perforant path (Fig. 3A (b)) and hippocampus (Fig. 3A (c)) of TG-shNgR mice decreased in comparison with TG-vector mice. This data, to some extent, supports the idea that the $A \beta$ is released, at least partially from naked region of myelinated axon-NORs. More detail evidences about the generation of $A \beta$ in this area need to be clarified furtherly. If it is the case, reduced $A \beta$ production in the perforant path might have functional effect directly and/or contribute to the decreased $A \beta$ level in the hippocampus and cortex. It might be likely that $\mathrm{NgR}$ reduction in the perforant path lowered the $A \beta$ level in this pathway and then reduced the "spread" of $A \beta$ to the hippocampus and cortex, through prion-like propagation [41] or functional activity [9].

In contrast to our results, Park et al. have demonstrated that NgR knockout in APP/PS1 mice results in an increase in amyloid plaques and $A \beta$ peptides in both the cortex and hippocampus [22]. We speculate that different manipulation on NgR gene might be the major reason that we observed results opposite to theirs. Genetic loss of NgR might affect the function of the whole brain and even the developmental processes of the APP/ PS1 mice. In our study, NgR expression was selectively reduced in the perforant path as we are more interested in the role of the perforant path in the development of amyloid pathology.

Neuroinflammation characterized by astrocyte and microglia activation is another common AD pathology $[38,39]$ that can be induced by amyloid deposition and neuronal injury. In this study, selective NgR knockdown was shown to inhibit microglia and astrocyte activation in the brain of APP/PS1 mice (Fig. 4). It is reasonable that reduced amyloid deposition and glial activation leads to improved cognitive function of APP/PS1 mice with less $\mathrm{NgR}$ in the perforant path, although the effect of NgR knockdown on cognitive function in wild type mice is not clear. Studies have demonstrated the role of $\mathrm{NgR} 1$ as a critical gate to both experience-dependent learning and anatomical plasticity $[42,43]$ and lacking NgR1 impairs short-term object memory [18]. However, overexpression of the NgR1 gene in forebrain neurons impairs the formation of lasting memories, suggesting impaired plasticity when $\mathrm{NgR} 1$ cannot be downregulated as needed [44]. Consistently, expressions of NgR are increased in patients with AD [19], where NgR knockdown could be beneficial.

A $\beta$ reduction could be the result of decreased production and/or increased clearance of this peptide. Several studies have suggested $\mathrm{NgR}$ modulates $\mathrm{A} \beta$ levels in the brain and influences the cognitive functions of $\mathrm{AD}$ animals, even though the results are conflicting [21-23, 45]. It is suggested that $\mathrm{NgR} 2$ interferes with the interaction of APP and BACE- 1 and reduces the cleavage of APP by BACE-1 [45]. Our results indicate that the BACE-1 protein level was not affected by knocking down $\mathrm{NgR}$ (Fig. 5A (a, b)) and downregulation of NgR decreased both $\alpha$-secretase and $\beta$-secretase cleavage products as well as the total protein level of APP (Fig. 5A (a, b)). It is not known whether $\mathrm{NgR}$ could suppress both $\alpha$ secretase and $\beta$-secretase activities; however, it is possible that NgR regulates APP processing by affecting the APP protein level without influencing the expressions and activities of the secretases. APP protein levels are affected by both gene expression and protein processing in the cells. Here, the NgR level had no effect on the mRNA level of APP, so we further investigated whether NgR played a role in APP processing.

We already know that full-length APP is synthesized in the endoplasmic reticulum (ER) and transported to the cell surface through the Golgi/trans-Golgi network (TGN), where APP can be cleaved by $\beta$-secretase and then by $\gamma$-secretase complex to produce A $\beta$. Alternatively, APP can be cleaved by $\alpha$-secretase within the A $\beta$ domain to release soluble APP $\alpha$ and preclude $A \beta$ generation. APP can also be internalized within clathrincoated vesicles and may be recycled back to the cell surface, retrieved back to the TGN, or processed in endosomes [46, 47]. It has been proposed that Golgi and endosomes are the major intracellular compartments of APP being processed into $A \beta$ [48-52]. It has been reported that APP protein can be degenerated through both the proteasomal and lysosomal pathways [53] and inhibition of lysosomal or proteasomal degradation processes will cause the accumulation of APP fragments 
and $\mathrm{A} \beta$ production. Consistently, enhancing lysosomal cathepsin activity ameliorates $A \beta$ toxicity $[54,55]$ and restoring the autophagy-lysosomal pathway reduced $A \beta$ accumulation and rescued memory performance [56]. These studies suggest that APP traffic to lysosomes may reduce the APP protein level and $A \beta$ production.

$\mathrm{NgR}$ is known to increase the GTP bound state of the neuronal cytoskeleton regulatory factor RhoA, a Rho GTPase family member, to activate the RhoA/ROCK pathway [40]. Notably, RhoA/ROCK2 pathway is involved in APP degradation in lysosome and inhibition of ROCK2 activity reduces amyloidogenic process from APP [2]. Our result showed that the levels of RhoA and ROCK2 are correlated with NgR levels both in APP/PS1 mice and APPswe/HEK293 cells (Fig. 6A, B). So it is possible that $\mathrm{NgR}$ might regulate APP protein level through Rho/ROCK pathway. Indeed, inhibition of the activity of ROCK2 kinase could reverse the elevation of APP protein induced by overexpression of NgR (Fig. 6C, D). Further, it was shown that APP localized more strongly to LAMP1-positive compartments following knockdown of $\mathrm{NgR}$, suggesting that $\mathrm{NgR}$ suppresses APP traffic to lysosome. Together, these results implicate $\mathrm{NgR}$ in APP degradation and $A \beta$ production through Rho/ROCK2 signaling pathway (Fig. 7). As a glycosylphosphatidylinositol (GPI)-anchored protein lacking intracellular component, $\mathrm{NgR}$ does not transduce signals directly, but instead recruits co-receptor molecules such as p75NTR or TROY [40]. However, how $\mathrm{NgR}$ activates Rho/ROCK2 pathway is not well understood yet. The plexin receptors regulate cell adhesion, migration, and guidance, with their intracellular region interacts directly with small GTPases of the Rho family $[57,58]$. Plexins are widely expressed in neurons, performing critical functions in axon guidance and signal transduction [59]. It is of interest to investigate functional correlation between $\mathrm{NgR}$ and plexin receptors.

\section{Conclusions}

In summary, our study suggests that $\mathrm{NgR}$ plays a critical role in APP processing through Rho/ROCK signaling pathway, and NgR knockdown in the perforant path reduces the APP level and A $\beta$ production, which might account for the improved synaptic and cognitive function in the APP/PS1 mice. These findings provide a better understanding of the roles of the perforant path and $\mathrm{NgR}$ in $\mathrm{AD}$ pathogenesis and offer a novel therapeutic strategy and approaches for the treatment of AD.

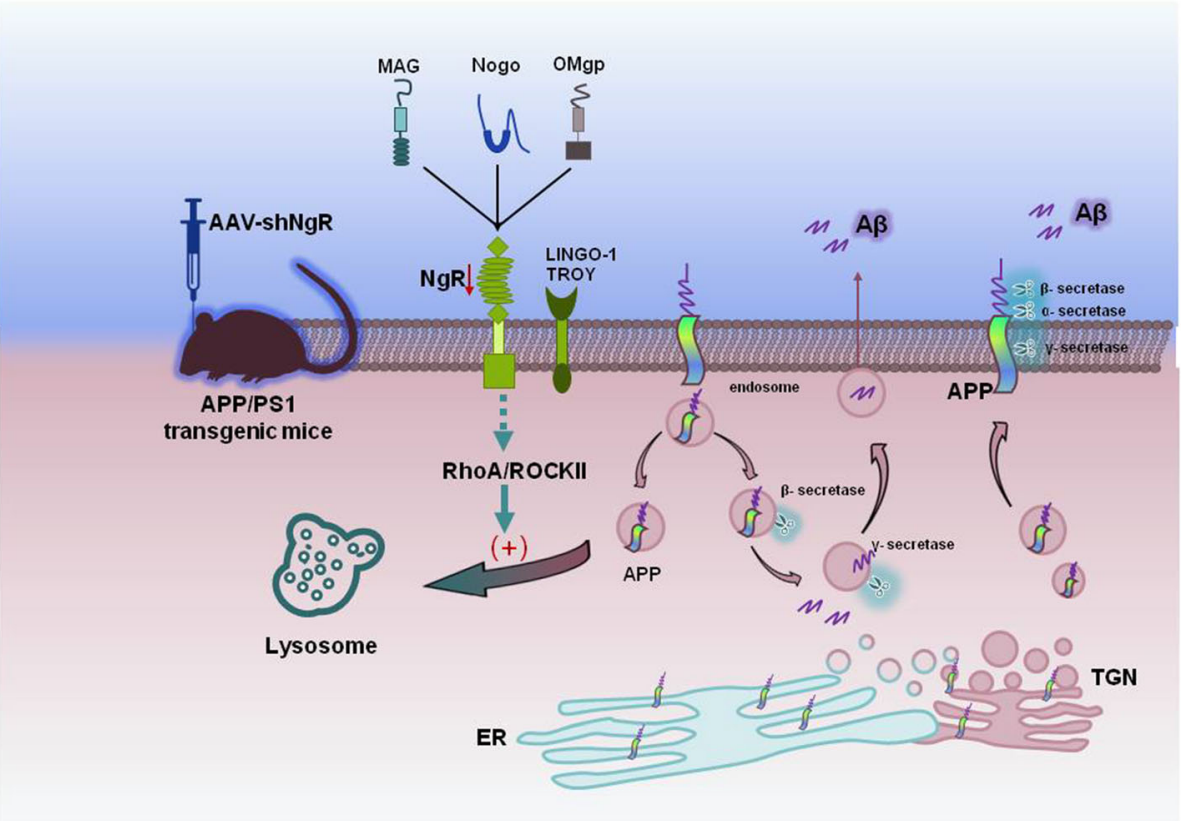

Fig. 7 The proposed effect of NgR reduction on APP traffic to lysosome through Rho/ROCK2 pathway. Full-length APP is synthesized in the endoplasmic reticulum (ER) and transported to the cell surface or endosomes/lysosomes. Once APP is transported to the cell surface, it undergoes amyloidogenic or non-amyloidogenic processing by $\beta$-secretase or a-secretase cleavage. While partial APP is internalized and delivered to endosome, a fraction of endocytosed APP molecules is recycled back to the cell surface, and other fractions are either processed in the endosome to release $A \beta$ or delivered to lysosome for degradation. NgR reduction suppresses the downstream Rho/ROCK2 signaling pathway which enhances APP traffic to lysosomes, thus may reduce APP distribution to other cellular compartments and decrease A $\beta$ production 


\section{Supplementary information}

Supplementary information accompanies this paper at https://doi.org/10. 1186/s13195-020-00616-3.

Additional file 1: Figure S1. Evaluation of the infection efficiency after injection of AAV expressing plasmids pAKD-CMV-bGlobin-eGFP-H1-shNgR into the perforant path three months. Fluorescence image of AAVmediated GFP expression at target area (B) and expressions of $\mathrm{NgR}$ in the perforant path by Western blotting (C Representative blot image and D densitometry analysis of protein levels). PP: perforant path. Scale bars: $500 \mu \mathrm{m}$. The statistical analysis was performed by Student's $t$-test. * $P<$ 0.05

Additional file 2: Figure S2. APP expression levels in APPswe/HEK293 cells treated with different concentration of $\mathrm{Y}-27632$ or Fasudil for $10 \mathrm{~h}$. A Representative blot image and $\mathbf{B}$ densitometry analysis of APP levels after incubating Y-27632. C Representative blot image and D densitometry analysis of APP levels after incubating Fasudil. The statistical analysis was performed by one-way ANOVA. $* P<0.05 ; * *<0.01$.

\section{Abbreviations}

NgR: Nogo receptor; AB: Amyloid beta; AD: Alzheimer's disease; AAV: Adenoassociated virus; ANOVA: Analysis of variance; APP: Amyloid beta precursor protein; EC: Entorhinal cortex; ROCK: Rho-associated protein kinases; BACE1: $\beta$-Site amyloid precursor protein-cleaving enzyme 1; CTFa and CTF $\beta$ : C-terminal fragments of APP; GFAP: Glial fibrillary acidic protein; Iba1: Ionized calcium-binding adaptor molecule-1; ISF: Interstitial fluid PS1: Presenilin 1; SAPP $\beta$ : Soluble peptide APP $\beta$; shRNA: Short hairpin; NOR: Node of Ravier; MAG: Myelin-associated glycoprotein; OMgp: Oligodendrocyte myelin glycoprotein; LTP: Long-term potentiation; PPF: Paired-pulse facilitation; aCSF: Artificial cerebrospinal fluid; fEPSPs: Field excitatory postsynaptic potentials; HFS: High-frequency stimulation; SiRNA: Small interfering RNA; ER: Endoplasmic reticulum; TGN: Trans-Golgi network; GPI: Glycosylphosphatidylinositol

\section{Acknowledgements}

Not applicable.

\section{Authors' contributions}

RJ played a major role in performing experiments and analyzing the data, as well as writing the initial draft of the manuscript. RJ, BW, LL, NL, and YM performed the experiments. SL, JZ, QHM, and XFW supervised the entire study and designed the experiments. APL, LML, RXG, and QFL participated in the data analysis and revised the manuscript. SL, JZ, and XFW provided financial support for the study. All authors have read and approved the final version of the manuscript.

\section{Funding}

This work was supported by grants from the Liaoning Revitalization Talents Program (XLYC1902044, XLYC1808031), Liaoning Provincial Key R\&D Program (2019020048-JH2/103), National Natural Sciences Foundation of China (81571061, 81371223, 81671111 and 81870897), and National Major Scientific and Technological Special Project for "Significant New Drugs Development" (2019zx09301102).

\section{Availability of data and materials}

All data generated in this study are available from the corresponding author on reasonable request.

\section{Ethics approval and consent to participate}

This study was carried out in accordance with the recommendations of "the National Institute of Health Guide for the Care and Use of Laboratory Animals" (NIH Publications No. 80-23, revised 1996). The animals were handled in accordance with the guidelines of the Committees of Animal Use and Protection, and all efforts were made to minimize the number of animals used and their suffering. All experimental and animal protocols were approved by the animal studies committees of Dalian Medical University (ethics committee approval permit no. L2013011).

\section{Consent for publication}

Not applicable.

\section{Competing interests}

The authors declare that they have no competing interests.

Received: 31 December 2019 Accepted: 7 April 2020

Published online: 24 April 2020

\section{References}

1. Furusawa K, Takasugi T, Chiu YW, Hori Y, Tomita T, Fukuda M, et al. CD2associated protein (CD2AP) overexpression accelerates amyloid precursor protein (APP) transfer from early endosomes to the lysosomal degradation pathway. J Biol Chem. 2019;294(28):10886-99.

2. Herskowitz JH, Feng Y, Mattheyses AL, Hales CM, Higginbotham LA, Duong DM, et al. Pharmacologic inhibition of ROCK2 suppresses amyloid-beta production in an Alzheimer's disease mouse model. J Neurosci. 2013;33(49): 19086-98.

3. Wang J, Shan C, Cao W, Zhang C, Teng J, Chen J. SCG10 promotes nonamyloidogenic processing of amyloid precursor protein by facilitating its trafficking to the cell surface. Hum Mol Genet. 2013;22(24):4888-900.

4. Gómez-Isla T, Price JL, McKeel DW Jr, Morris JC, Growdon JH, Hyman BT. Profound loss of layerll entorhinal cortex neurons occurs in very mild Alzheimer's disease. J Neurosci. 1996;16(14):4491-500.

5. Su Y, Ni B. Selective deposition of amyloid-beta protein in the entorhinaldentate projection of a transgenic mouse model of Alzheimer's disease. J Neurosci Res. 1998;53(2):177-86.

6. Buxbaum JD, Thinakaran G, Koliatsos V, O'Callahan J, Slunt HH, Price DL, et al. Alzheimer amyloid protein precursor in the rat hippocampus: transport and processing through the perforant path. J Neurosci. 1998; 18(23):9629-37.

7. Scheff SW, Price DA, Schmitt FA, Mufson EJ. Hippocampal synaptic loss in early Alzheimer's disease and mild cognitive impairment. Neurobiol Aging 2006;27(10):1372-84.

8. Hyman BT, Van Hoesen GW, Kromer LJ, Damasio AR. Perforant pathway changes and the memory impairment of Alzheimer's disease. Ann Neurol. 1986;20(4):472-81.

9. Cirrito JR, Yamada KA, Finn MB, Sloviter RS, Bales KR, May PC, et al. Synaptic activity regulates interstitial fluid amyloid-beta levels in vivo. Neuron. 2005; 48(6):913-22.

10. Xu DE, Zhang WM, Yang ZZ, Zhu HM, Yan KLS, Bagnard D, et al. Amyloid precursor protein at node of Ranvier modulates nodal formation. Cell Adhes Migr. 2014;8(4):396-403.

11. Karlsson TE, Wellfelt K, Olson L. Spatiotemporal and long lasting modulation of 11 key Nogo signaling genes in response to strong neuroexcitation. Front Mol Neurosci. 2017;10:94.

12. McGee AW, Yang Y, Fischer QS, Daw NW, Strittmatter SM. Experience-driven plasticity of visual cortex limited by myelin and Nogo receptor. Science. 2005;309(5744):2222-6.

13. Fournier $A E$, GrandPre T, Strittmatter SM. Identification of a receptor mediating Nogo-66 inhibition of axonal regeneration. Nature. 2001; 409(6818):341-6.

14. Zuo YC, Li HL, Xiong NX, Shen JY, Huang YZ, Fu P, Zhao HY. Overexpression of tau rescues Nogo-66-induced neurite outgrowth inhibition in vitro. Neurosci Bull. 2016:32(6):577-84.

15. GrandPré T, Nakamura F, Vartanian T, Strittmatter SM. Identification of the Nogo inhibitor of axon regeneration as a reticulon protein. Nature. 2000; 403(6768):439-44.

16. Liu Y, Ma C, Li H, Shen H, Li X, Fu X, et al. Nogo-A/Pir-B/TrkB signaling pathway activation inhibits neuronal survival and axonal regeneration after experimental intracerebral hemorrhage in rats. J Mol Neurosci. 2019;69(3): 360-70.

17. Rahmanzadeh $R$, Sahraian MA, Rahmanzade $R$, Rodriguez M. Demyelination with preferential MAG loss: a complex message from MS paraffin blocks. J Neurol Sci. 2018;385:126-30.

18. Raiker SJ, Lee H, Baldwin KT, Duan Y, Shrager P, Giger RJ. Oligodendrocytemyelin glycoprotein and Nogo negatively regulate activity-dependent synaptic plasticity. J Neurosci. 2010;30(37):12432-45.

19. Zhu HY, Guo HF, Hou HL, Liu YJ, Sheng SL, Zhou JN. Increased expression of the Nogo receptor in the hippocampus and its relation to the neuropathology in Alzheimer's disease. Hum Pathol. 2007;38(3):426-34.

20. Masliah E, Xie F, Dayan S, Rockenstein E, Mante M, Adame A, et al. Genetic deletion of Nogo/Rtn4 ameliorates behavioral and neuropathological 
outcomes in amyloid precursor protein transgenic mice. Neuroscience. 2010;169(1):488-94.

21. Fang Y, Yao L, Li C, Wang J, Wang J, Chen S, et al. The blockage of the Nogo/NgR signal pathway in microglia alleviates the formation of $A \beta$ plaques and tau phosphorylation in APP/PS1 transgenic mice. J Neuroinflammation. 2016;13(1):56.

22. Park JH, Gimbel DA, GrandPre T, Lee JK, Kim JE, Li W, et al. Alzheimer precursor protein interaction with the Nogo-66 receptor reduces amyloidbeta plaque deposition. J Neurosci. 2006;26(5):1386-95.

23. Park JH, Widi GA, Gimbel DA, Harel NY, Lee DH, Strittmatter SM. Subcutaneous Nogo receptor removes brain amyloid-beta and improves spatial memory in Alzheimer's transgenic mice. J Neurosci. 2006;26(51):13279-86.

24. Morris R. Developments of a water-maze procedure for studying spatial learning in the rat. J Neurosci Methods. 1984;11(1):47-60.

25. Xu L, Qiu X, Wang S, Wang Q, Zhao XL. NMDA receptor antagonist MK801 protects against 1-bromopropane-induced cognitive dysfunction. Neurosci Bull. 2019;35(2):347-61

26. Akar F, Mutlu O, Komsuoglu Celikyurt I, Bektas E, Tanyeri P, Ulak G, et al. Effects of 7-NI and ODQ on memory in the passive avoidance, novel object recognition, and social transmission of food preference tests in mice. Med Sci Monit Basic Res. 2014;20:27-35.

27. Nakamura K, Ito M, Liu Y, Seki T, Suzuki T, Arai H. Effects of single and repeated electroconvulsive stimulation on hippocampal cell proliferation and spontaneous behaviors in the rat. Brain Res. 2013;1491:88-97.

28. Shan $L$, Ma $D$, Zhang $C$, Xiong $W$, Zhang $Y$. miRNAs may regulate GABAergic transmission associated genes in aged rats with anesthetics-induced recognition and working memory dysfunction. Brain Research. 2017;1670: 191-200.

29. Wang B, Wu Q, Lei L, Sun H, Michael N, Zhang X, et al. Long-term social isolation inhibits autophagy activation, induces postsynaptic dysfunctions and impairs spatial memory. Exp Neurol. 2019;311:213-24.

30. Jin WS, Shen $L L$, Bu XL, Zhang WW, Chen SH, Huang ZL, et al. Peritoneal dialysis reduces amyloid-beta plasma levels in humans and attenuates Alzheimer-associated phenotypes in an APP/PS1 mouse model. Acta Neuropathol. 2017;134(2):207-20.

31. Macauley SL, Stanley M, Caesar EE, Yamada SA, Raichle ME, Perez R, et al. Hyperglycemia modulates extracellular amyloid- $\beta$ concentrations and neuronal activity in vivo. J Clin Invest. 2015;125(6):2463-7.

32. Klapdor K, van der Staay FJ. The Morris water-escape task in mice: strain differences and effects of intra-maze contrast and brightness. Physiol Behavior. 1996;60(5):1247-54

33. Zhang MY, Zheng CY, Zou MM, Zhu JW, Zhang Y, Wang J, et al. Lamotrigine attenuates deficits in synaptic plasticity and accumulation of amyloid plaques in APP/PS1 transgenic mice. Neurobiol Aging. 2014;35(12): 2713-25.

34. Sri S, Pegasiou CM, Cave CA, Hough K, Wood N, Gomez-Nicola D, et al. Emergence of synaptic and cognitive impairment in a mature-onset APP mouse model of Alzheimer's disease. Acta Neuropathol Commun. 2019;7(1):25.

35. Wang ZX, Tan L, Liu J, Yu JT. The essential role of soluble A oligomers in Alzheimer's disease. Mol Neurobiol. 2016;53(3):1905-24.

36. Liu CC, Zhao N, Yamaguchi Y, Cirrito JR, Kanekiyo T, Holtzman DM, et al. Neuronal heparan sulfates promote amyloid pathology by modulating brain amyloid- $\beta$ clearance and aggregation in Alzheimer's disease. Sci Transl Med. 2016;8(332):332ra44.

37. Stanley M, Macauley SL, Caesar EE, Koscal L, Moritz W, Robinson GO, et al. The effects of peripheral and central high insulin on brain insulin signaling and amyloid- $\beta$ in young and old APP/PS1 mice. J Neurosci. 2016;36(46): 11704-15.

38. Henstridge CM, Hyman BT, Spires-Jones TL. Beyond the neuron-cellular interactions early in Alzheimer disease pathogenesis. Nat Rev Neurosci. 2019;20(2):94-108.

39. Zhang R, Miller RG, Madison C, Jin X, Honrada R, Harris W, et al. Systemic immune system alterations in early stages of Alzheimer's disease. J Neuroimmunol. 2013;256(1-2):38-42.

40. McDonald CL, Bandtlow C, Reindl M. Targeting the Nogo receptor complex in diseases of the central nervous system. Curr Med Chem. 2011;18(2):234-44.

41. Walker LC. Prion-like mechanisms in Alzheimer disease. Handb Clin Neurol. 2018:153:303-19.

42. Karlsson TE, Smedfors G, Brodin AT, Åberg E, Mattsson A, Högbeck I, et al. NgR1: a tunable sensor regulating memory formation, synaptic, and dendritic plasticity. Cereb Cortex. 2016;26(4):1804-17.
43. Park Jl, Frantz MG, Kast RJ, Chapman KS, Dorton HM, Stephany CÉ, et al. Nogo receptor 1 limits tactile task performance independent of basal anatomical plasticity. PLoS One. 2014;9(11):e112678.

44. Karlén A, Karlsson TE, Mattsson A, Lundströmer K, Codeluppi S, Pham TM, et al. Nogo receptor 1 regulates formation of lasting memories. Proc Natl Acad Sci U S A. 2009;106(48):20476-81.

45. Zhou X, Hu X, He W, Tang X, Shi Q, Zhang Z, et al. Interaction between amyloid precursor protein and Nogo receptors regulates amyloid deposition. FASEB J. 2011;25(9):3146-56.

46. Nordstedt C, Caporaso GL, Thyberg J, Gandy SE, Greengard P. Identification of the Alzheimer beta/A4 amyloid precursor protein in clathrin-coated vesicles purified from PC12 cells. J Biol Chem. 1993;268(1):608-12.

47. Caporaso GL, Takei K, Gandy SE, Matteoli M, Mundigl O, Greengard P, et al. Morphologic and biochemical analysis of the intracellular trafficking of the Alzheimer beta/A4 amyloid precursor protein. J Neurosci. 1994;14(5):3122-38.

48. Toh WH, Tan JZ, Zulkefli KL, Houghton FJ, Gleeson PA. Amyloid precursor protein traffics from the Golgi directly to early endosomes in an Arl5b- and AP4-dependent pathway. Traffic. 2017;18(3):159-75.

49. Kinoshita A, Fukumoto H, Shah T, Whelan CM, Irizarry MC, Hyman BT. Demonstration by FRET of BACE interaction with the amyloid precursor protein at the cell surface and in early endosomes. J Cell Sci. 2003;116: $3339-46$.

50. Toh WH, Chia PZC, Hossain MI, Gleeson PA. GGA1 regulates signaldependent sorting of BACE1 to recycling endosomes, which moderates $A \beta$ production. Mol Biol Cell. 2018;29(2):191-208.

51. Chia PZ, Toh WH, Sharples R, Gasnereau I, Hill AF, Gleeson PA. Intracellular itinerary of internalised $\beta$-secretase, BACE1, and its potential impact on $\beta$ amyloid peptide biogenesis. Traffic. 2013;14(9):997-1013.

52. Burgos PV, Mardones GA, Rojas AL, da Silva LL, Prabhu Y, Hurley JH, et al. Sorting of the Alzheimer's disease amyloid precursor protein mediated by the AP-4 complex. Dev Cell. 2010;18(3):425-36.

53. Shi Z, Chen T, Yao Q, Zheng L, Zhang Z, Wang J, et al. The circular RNA ciRS-7 promotes APP and BACE1 degradation in an NF-KB-dependent manner. FEBS J. 2017;284(7):1096-109.

54. Spilman P, Podlutskaya N, Hart MJ, Debnath J, Gorostiza O, Bredesen D, et al. Inhibition of mTOR by rapamycin abolishes cognitive deficits and reduces amyloid- $\beta$ levels in a mouse model of Alzheimer's disease. PLoS One. 2010;5(4):e9979.

55. Hwang J, Estick CM, Ikonne US, Butler D, Pait MC, Elliott LH, et al. The role of lysosomes in a broad disease-modifying approach evaluated across transgenic mouse models of Alzheimer's disease and Parkinson's disease and models of mild cognitive impairment. Int J Mol Sci. 2019;20(18):4432.

56. Caccamo A, Majumder S, Richardson A, Strong R, Oddo S. Molecular interplay between mammalian target of rapamycin (mTOR), amyloid-beta, and tau: effects on cognitive impairments. J Biol Chem. 2010;285(17):13107-20.

57. Zhang L, Buck M. Molecular dynamics simulations reveal isoform specific contact dynamics between the plexin rho GTPase binding domain (RBD) and small rho GTPases Rac1 and Rnd1. J Phys Chem B. 2017;121(7):1485-98.

58. Wang H, Hota PK, Tong Y, Li B, Shen L, Nedyalkova L, et al. Structural basis of Rnd1 binding to plexin Rho GTPase binding domains (RBDs). J Biol Chem. 2011;286(29):26093-106.

59. Negishi M, Oinuma I, Katoh H. Plexins: axon guidance and signal transduction. Cell Mol Life Sci. 2005;62(12):1363-71.

\section{Publisher's Note}

Springer Nature remains neutral with regard to jurisdictional claims in published maps and institutional affiliations.

\section{Ready to submit your research? Choose BMC and benefit from:}

- fast, convenient online submission

- thorough peer review by experienced researchers in your field

- rapid publication on acceptance

- support for research data, including large and complex data types

- gold Open Access which fosters wider collaboration and increased citations

- maximum visibility for your research: over $100 \mathrm{M}$ website views per year

At BMC, research is always in progress.

Learn more biomedcentral.com/submissions 